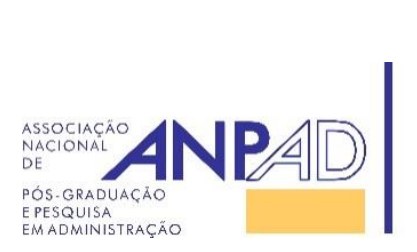

Disponível em

http://www.anpad.org.br/rac

RAC, Rio de Janeiro, v. 20, n. 3, art. 3, pp. 305-327, Maio/Jun. 2016

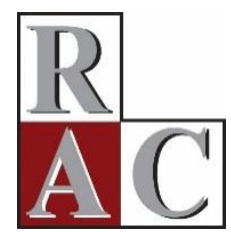

$(\mathrm{cc})$ EY

\title{
O Ensino de Empreendedorismo com Fundamento na Teoria Effectuation
}

Teaching Entrepreneurship Using Effectuation Theory

Marcus Alexandre Yshikawa Salusse ${ }^{1}$

Tales Andreassi ${ }^{1}$

Fundação Getulio Vargas ${ }^{1}$

Artigo recebido em 04.03.2015. Última versão recebida em 30.11.2015. Aprovado em 05.12.2015. Publicado online em 23.02.2016. 


\title{
Resumo
}

Em função da baixa consolidação das metodologias de ensino voltadas ao empreendedorismo que sejam suportadas por fundamentos teóricos consistentes, o objetivo desta pesquisa é compreender como professores ensinam empreendedorismo com fundamento na teoria effectuation. A pesquisa utiliza a metodologia de estudo de caso múltiplo - cinco experiências em quatro países - com intuito de compreender o contexto e a estrutura dos cursos, as metodologias de ensino utilizadas e a percepção dos docentes sobre as experiências de ensino. Como principais resultados, destaca-se a prática do modelo dinâmico de effectuation como elemento integrador presente em todos os casos, a identificação de metodologias de ensino emergentes e a categorização das metodologias de ensino em função das dimensões e comportamentos associados à teoria. Além disso, o estudo estabelece as primeiras relações da teoria com intenção de empreender e propõe que antecedentes pessoais do indivíduo, no caso, a cultura e educação formal, sejam testados em futuras pesquisas.

Palavras-chave: empreendedorismo; ensino de empreendedorismo; teoria effectuation; estudo de caso múltiplo; internacional.

\begin{abstract}
Due to the low consolidation of entrepreneurship teaching methodologies supported by consistent theoretical foundations, the objective of this research is to understand how professors teach entrepreneurship using effectuation theory. The research uses the multiple case study methodology - five teaching experiences in four different countries - in order to understand the context and the structure of the courses, the methodologies applied and the perception of professors regarding the teaching-learning experiences. As main results, it emphasizes the practice of the dynamic model of effectuation as the integrating element in all cases, the identification of emerging teaching methodologies and the categorization of teaching methodologies according to the dimensions and behavior associated with the theory. In addition, the study establishes initial relationships between effectuation and entrepreneurial intention and the need for the field to consider the individual's personal history, such as culture and formal education, to be tested in future research.
\end{abstract}

Key words: entrepreneurship; entrepreneurship teaching; effectuation theory; multiple case study; international. 


\section{Introdução}

A importância do empreendedorismo para o desenvolvimento social e econômico tem sido demonstrada por meio da geração de emprego e renda (Haltiwanger, Jarmin, \& Miranda, 2009; Rideout \& Gray, 2013; Wennekers \& Thurik, 1999). Atualmente, gestores públicos vislumbram no empreendedorismo uma alternativa para o desenvolvimento regional (Sarfati, 2013). Neste contexto, surgiram, desde a década de 1940, diferentes abordagens teóricas com o intuito de compreender a lógica e as ações subjacentes ao comportamento empreendedor, dentre elas a teoria effectuation (Sarasvathy, 2001a), foco deste estudo. A teoria effectuation surge como alternativa à lógica causal predominante fundamentada na teoria econômica tradicional, e se consolidou nos últimos anos como perspectiva emergente de maior impacto e generalidade (Fisher, 2012).

De acordo com a teoria effectuation (Sarasvathy, 2001a, 2008), empreendedores (a) identificam oportunidades a partir de recursos existentes, (b) tomam decisões de investimento com base no que estão dispostos a perder, (c) aproveitam as contingências e (d) estabelecem relações estratégicas com stakeholders. Estudo realizado por Chandler, DeTienne, McKelvie e Mumford (2011) para validação do construto propõe que o effectuation seja formado por quatro dimensões: (a) experimentação, (b) perda aceitável, (c) flexibilidade e (d) pré-acordos. Fisher (2012), por sua vez, define comportamentos associados a cada uma dessas dimensões no nível das ações individuais e estabelece proposições sobre os conceitos: (a) oportunidades acessíveis, (b) orientação para ação individual ou do time, (c) comunidades empreendedoras e (d) restrição de recursos. Embora o modelo teórico de effectuation tenha evoluído nos últimos anos (Chandler, DeTienne, McKelvie, \& Mumford, 2011; Fisher, 2012; Sarasvathy, 2001a, 2008; Sarasvathy \& Dew, 2005), uma de suas vertentes, a associada à investigação das metodologias de ensino adequadas ao desenvolvimento do comportamento effectual, encontra-se, ainda hoje, pouco explorada.

Isto porque, em decorrência da tipificação desenvolvida por Fisher (2012), é possível categorizar metodologias de ensino utilizadas por docentes que adotam a teoria como fundamento de suas disciplinas, em função dos comportamentos a ela associados. É importante notar que há, na literatura, consenso sobre a necessidade de metodologias de ensino diferentes das utilizadas até então (Neck \& Greene, 2011; Sarasvathy, 2008; Sarasvathy \& Venkataraman, 2011), entretanto, a revisão conduzida por Perry, Chandler e Markova (2012) não faz menção a estudos que tenham abordado o fenômeno do ponto de vista da educação empreendedora. Além disso, um levantamento realizado em três bases de dados nacionais (SciELO, Spell e EnANPAD) e três internacionais (Scopus, EBSCO e ISI Web of Knowledge), na busca por artigos que contivessem em seu título e/ou resumo os termos effectuation e education ou effectuation e educação ou, ainda, effectuation e ensino, resultou na identificação de apenas um artigo (Maritz \& Brown, 2013). No entanto, a análise do artigo evidenciou tratar-se de objeto alheio a esta discussão, sendo a palavra effectuation associada à metodologia utilizada para avaliação do efeito de programa vocacional de educação empreendedora na autoeficácia dos participantes.

Já o objetivo geral deste estudo é compreender como professores ensinam empreendedorismo com fundamento na teoria effectuation e categorizar as metodologias utilizadas em função das dimensões propostas por Chandler et al. (2011) e comportamentos definidos por Fisher (2012). Para tanto, foram estabelecidos quatro objetivos específicos: (a) descrever o contexto em que ocorrem as experiências em educação empreendedora, (b) identificar a estrutura dos cursos, (c) identificar as metodologias de ensino utilizadas e (d) analisar as percepções dos docentes sobre as experiências em educação empreendedora com fundamento na teoria effectuation. Esta pesquisa, de natureza teóricoempírica, busca preencher a lacuna teórica caracterizada pela ausência de categorização de metodologias de ensino com fundamento na teoria effectuation em função de suas dimensões e comportamentos. A pesquisa também pretende identificar novos insigths e relações entre as dimensões do construto e conceitos que surjam da investigação do uso da teoria no contexto do ensino de empreendedorismo.

A pesquisa faz isto ao investigar cinco experiências em educação empreendedora em quatro países diferentes e, ao fazê-lo, gera importantes contribuições. No âmbito teórico, analisa e compara casos de 
ensino em diferentes contextos e identifica o elemento integrador comum à utilização da teoria no ensino de empreendedorismo, a prática do modelo dinâmico de effectuation. Em segundo lugar, o artigo avança na literatura ao identificar metodologias de ensino emergentes e ao categorizar, por meio dos casos analisados, as metodologias de ensino utilizadas pelos docentes para desenvolver comportamentos associados às dimensões (a) experimentação, (b) flexibilidade, (c) perda aceitável e (d) pré-acordos, que formam o construto effectuation. Em terceiro lugar, o estudo permite insights iniciais a respeito da influência da teoria effectuation sobre a intenção de empreender, além de detectar a necessidade de se incorporar na literatura sobre o tema conceitos e temáticas associados aos antecedentes individuais, a exemplo do contexto cultural no qual se insere o indivíduo e sua educação formal.

No contexto prático, o estudo identifica e categoriza metodologias de ensino associando-as aos comportamentos que se pretende desenvolver e permite que educadores possam utilizá-las de maneira adequada e consistente. Por fim, a descrição aprofundada de experiências em diferentes contextos permite aos educadores uma compreensão abrangente sobre o ensino de empreendedorismo com fundamento na teoria effectuation e serve como referência para o desenvolvimento de cursos regulares e atividades extracurriculares que utilizem a teoria no contexto das instituições de ensino superior.

\section{Referencial Teórico}

Neste referencial são apresentadas as principais correntes teóricas no campo do empreendedorismo e a relação existente entre as teorias e as metodologias de ensino a elas associadas, bem como os fundamentos da teoria effectuation.

\section{A evolução das perspectivas teóricas e o ensino de empreendedorismo}

A perspectiva teórica utilizada para análise do fenômeno empreendedor constitui o fundamento das metodologias utilizadas para seu ensino, em virtude dos pressupostos ontológicos e epistemológicos subjacentes (Alvarez \& Barney, 2013; Shane, 2012).

O foco inicial de pesquisa em empreendedorismo buscou identificar características distintivas da personalidade do empreendedor e teve como referência os estudos de McClelland (1961). Esta abordagem consiste em observar, descrever e mensurar as características do empreendedor (Tasic \& Andreassi, 2008) e utiliza aulas expositivas e empreendedores de sucesso convidados como principais metodologias de ensino. Suas limitações referem-se à ausência de variáveis ambientais em seus modelos, à necessidade de se reconhecer a complexidade do fenômeno quanto à definição de empreendedores e não-empreendedores, e ao conceito de sucesso associado a critérios exclusivamente econômicos (Neck \& Greene, 2011; Sarasvathy \& Venkataraman, 2011; Vesper \& Gartner, 1997).

A perspectiva processual, atualmente predominante, aborda o fenômeno como um processo linear e tem como objetivo analisar, prever e planejar as etapas do processo de criação de novos negócios. $\mathrm{O}$ nível de análise é da firma e as metodologias de ensino mais utilizadas são o estudo de caso e o desenvolvimento de planos de negócio (Christensen \& Carlile, 2009; Eckhardt \& Shane, 2013; Gartner, 1988). Sua principal limitação é o pressuposto da linearidade e previsibilidade, ou seja, de que seguidas corretamente as etapas do processo de planejamento, a probabilidade de sucesso do negócio tende a aumentar (Lange, Mollov, Pearlmutter, Singh, \& Bygrave, 2004). Além disso, a perspectiva processual não permite aferir como a interação entre empreendedores e a oportunidade ocorre (Dimov, 2011), motivo pelo qual a perspectiva cognitiva surge com o objetivo de identificar estruturas de conhecimento ou modelos mentais utilizados para avaliação de oportunidades e criação e desenvolvimento de negócios (Mitchell et al., 2002). Sob a perspectiva cognitiva, algumas metodologias de ensino utilizadas são os estudos de caso, as simulações, a pesquisa sistemática (Fiet \& Patel, 2006) e a identificação de oportunidades (DeTienne \& Chandler, 2004). Todavia, a abordagem cognitiva não resolve a discussão ontológica a respeito da natureza objetiva (Kirzner, 1979; Shane, 2012) ou subjetiva (Alvarez \& Barney, 2007, 2013) do construto oportunidade, o que limita o desenvolvimento do empreendedorismo como 
área de conhecimento (Dimov, 2011; Sarasvathy, 2004; Venkataraman, Sarasvathy, Dew, \& Forster, 2012).

Surge então a necessidade de nova abordagem do fenômeno empreendedor, e neste contexto emerge a perspectiva do empreendedorismo como método. Sob a perspectiva do empreendedorismo como método, as oportunidades são definidas como o resultado das ações e interações dos indivíduos com o ambiente externo (Sarasvathy \& Venkataraman, 2011). O objeto de análise é a relação do empreendedor com as coisas e/ou pessoas necessárias para que essas oportunidades existam, e a unidade de análise passa a incluir variáveis relacionadas às ações dos empreendedores e sua interação com os stakeholders por meio das quais é possível explorar essas oportunidades. O foco da análise é na interação entre elementos do ambiente interno do empreendedor (cognição do empreendedor) e elementos do ambiente externo (mercado, instituições, stakeholders) (Venkataraman et al., 2012).

O conceito de artefatos é central a esta perspectiva e implica na possibilidade de os indivíduos utilizarem seu conhecimento para agir sobre oportunidades. Em um ambiente em que não se pode prever ou controlar o futuro, a atenção volta-se para os mecanismos, estratégias, técnicas e princípios que empreendedores utilizam para agir de maneira empreendedora, tecendo a rede de relacionamentos e identificando recursos que permitirão criar e explorar oportunidades (Neck \& Greene, 2011; Sarasvathy \& Venkataraman, 2011). De maneira análoga, o ensino de empreendedorismo foca nos mecanismos de criação de artefatos empreendedores, ou seja, estratégias, técnicas e mecanismos utilizados por empreendedores para criação de novos negócios e novos mercados. Enquanto Venkataraman, Sarasvathy, Dew e Forster (2012) apresentam uma ampla lista de mecanismos de criação de artefatos, Neck e Greene (2011) sugerem quatro metodologias de ensino no contexto do empreendedorismo como método. Dentre os mecanismos enunciados, destaca-se o desenvolvimento da teoria de effectuation (Sarasvathy, 2001a), lógica relevante no contexto de desenvolvimento do empreendedorismo como área de conhecimento (Sarasvathy \& Venkataraman, 2011).

Não se pode perder de vista que o objetivo principal do ensino de empreendedorismo é, em última instância, contribuir para a geração de emprego e renda. Assim, compreender a evolução das técnicas de ensino e conhecer seus fundamentos teóricos permite ao docente uma análise crítica sobre a metodologia utilizada, suas fragilidades e suas contribuições para os objetivos de aprendizado (McMullan \& Long, 1987; Rideout \& Gray, 2013). Mas a pluralidade de abordagens e a dificuldade de avaliação dessas metodologias são fatores limitantes à legitimidade do exercício da docência na área. Ao mesmo tempo, o oferecimento de disciplinas de empreendedorismo continua crescendo e políticas públicas são constantemente direcionadas para estimular o empreendedorismo e o desenvolvimento de conteúdo empreendedor (Duval-Couetil, 2013; Katz, 2003).

\section{A teoria effectuation}

Originada da tese de doutorado de Sarasvathy (2001a, 2001b, 2008), a teoria effectuation tem como fundamento pressupostos diferentes dos utilizados pela lógica causal predominante no estudo do empreendedorismo e tem ganhado relevância e abrangência na última década (Fisher, 2012). A lógica causal e a lógica effectual são duas abordagens alternativas e não excludentes utilizadas por empreendedores no processo de criação e desenvolvimento de novos negócios (Sarasvathy, 2001a, 2008). É importante que se reconheça que os indivíduos utilizam tanto a lógica causal quanto a lógica effectual e as duas podem acontecer simultaneamente, de maneira sobreposta ou intercalada.

A lógica causal é consistente com conceitos econômicos neoclássicos (Kirzner, 1979), estratégia deliberada (Ansoff, 1965; Mintzberg, 1978), identificação de oportunidades por meio de busca sistemática (Fiet \& Patel, 2006) e desenvolvimento das oportunidades em função da previsão de retorno sobre investimentos (Drucker, 1998). Utilizando a lógica causal, o empreendedor define inicialmente os objetivos que pretende alcançar e identifica oportunidades oriundas de falhas de mercado que lhe permitam alcançar esses objetivos. Uma vez identificadas, as oportunidades são avaliadas e o empreendedor seleciona as oportunidades com vistas à maximização do retorno de seus investimentos e faz análise e planejamento das atividades necessárias para atingir resultados previamente estabelecidos 
por meio da exploração do seu conhecimento e recursos. Disso decorre que o processo causal estabelece um objetivo e foca na seleção dos meios necessários para alcançar esse objetivo, assumindo como pressuposto central do processo causal a lógica de que: "à medida que podemos prever o futuro, podemos controlá-lo" (Sarasvathy, 2001a, p. 251).

A lógica effectual, representada pela Figura 1, é consistente com conceitos de economia comportamental (Simon, 1959), estratégia emergente (Mintzberg, 1978), criação de oportunidades por meio da ação humana (Weick, 1979) e desenvolvimento das oportunidades em função dos acontecimentos imprevisíveis (March, 1978). Utilizando a lógica effectual, o empreendedor inicia o processo de criação do negócio com uma ideia genérica do que pretende fazer e utiliza os recursos existentes para interagir com potenciais stakeholders e agir sobre elementos que possa influenciar. A partir do resultado de suas decisões e das interações do empreendedor com seus stakeholders, o empreendedor decide mudar a ideia inicial do negócio à medida que esses stakeholders se comprometem e se engajam com o desenvolvimento conjunto do negócio e, com isso, novos recursos e novos objetivos emergem. De forma inversa, decorre que o processo effectual utiliza os recursos disponíveis e foca na seleção dos efeitos possíveis de se alcançar utilizando esses recursos, assumindo como pressuposto central do processo effectual a lógica de que: "à medida que podemos controlar o futuro, não precisamos prevê-lo" (Sarasvathy, 2001a, p. 251).

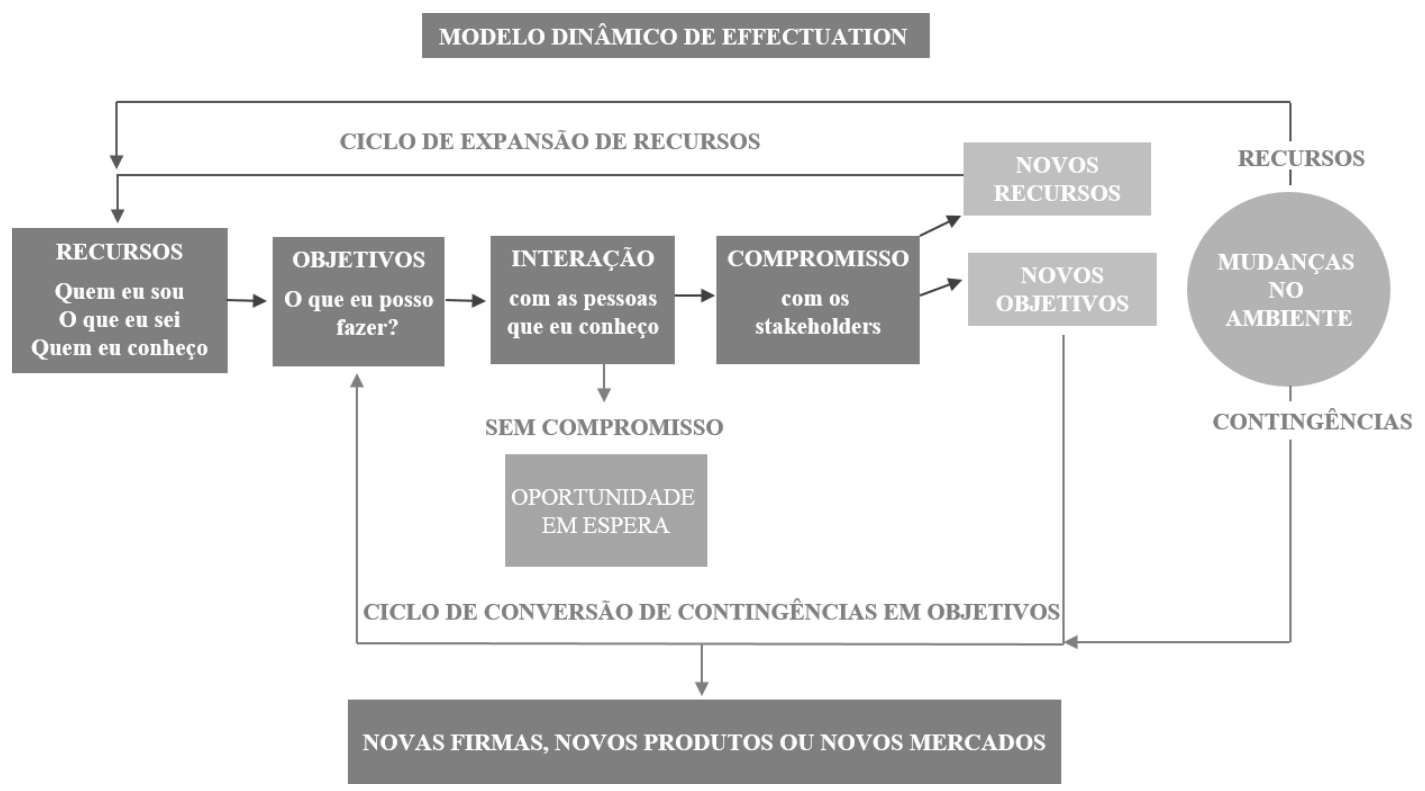

Figura 1. Modelo Dinâmico de Effectuation

Na Figura 1 é apresentado o modelo dinâmico de effectuation, que ilustra a forma como os recursos do empreendedor determinam seus objetivos primários, que por meio da interação com as pessoas consegue obter compromissos com stakeholders, permitindo ao empreendedor acessar novos recuros e estabelecer novos objetivos. Fonte: Adaptado de Read, S., Sarasvathy, S., Dew, N., Wiltbank, R., \& Ohlsson, A.-V. (2011). Effectual entrepreneurship. New York, NY: Routledge.

Decorre da literatura sobre a teoria effectuation que, quando aplicada ao empreendedorismo, embora não reduza a probabilidade de fracasso, diminui seu custo, pois permite ao empreendedor falhar mais rapidamente (Read, Sarasvathy, Dew, Wiltbank, \& Ohlsson, 2011; Sarasvathy, 2001a, 2008). De acordo com Sarasvathy (2001a, 2008), empreendedores que atuam sob a perspectiva effectual (a) identificam oportunidades a partir de recursos existentes, (b) tomam decisões de investimento com base no que estão dispostos a perder, (c) aproveitam as contingências e (d) estabelecem relações estratégicas com stakeholders. Os princípios da teoria atuam no sentido de que as eventuais falhas aconteçam mais rapidamente por meio da experimentação e, portanto, com menor nível de investimento do empreendedor, que utiliza os recursos disponíveis na identificação de oportunidades acessíveis, desenvolvidas por meio da interação com stakeholders, enquanto deixa aberta a possibilidade de maiores investimentos no futuro caso sejam validadas as hipóteses iniciais do novo negócio. Em estudo realizado para validação do construto, Chandler et al. (2011) propõem que effectuation é formado por quatro dimensões: (a) experimentação, ou seja, a utilização de diferentes abordagens de negócio para definição 
do conceito; (b) perda aceitável, isto é, estabelecimento do valor investido com base no montante que o empreendedor está disposto da perder; (c) flexibilidade, ou seja, adaptação da ideia inicial às contingências, circunstâncias e conhecimento adquirido; e (d) pré-acordos, isto é, estabelecimento de acordos estratégicos com stakeholders.

Fisher (2012), ao analisar como a teoria effectuation se traduz em comportamentos individuas, define comportamentos associados a cada uma das dimensões de Chandler et al. (2011) e, para cada um dos quatro comportamentos, tipifica ações que definem o conteúdo desses comportamentos. Além disso, avança no desenvolvimento da teoria ao estabelecer relações entre os conceitos: (a) oportunidades acessíveis, do inglês, actionable opportunities, identificadas a partir de recursos existentes e sobre as quais o empreendedor pode agir imediatamente; (b) orientação para ação individual ou do time, como forma de encontrar soluções funcionais e superar restrições de recursos; (c) rede de relacionamento, do inglês, entrepreneurial community ou entrepreneurial network, com a qual o empreendedor se relaciona e se engaja para obtenção de apoio para criar e desenvolver o negócio, além de testar e obter feedback sobre produtos e serviços; e (d) restrição de recursos, como fonte de criatividade e inovação. Em decorrência da tipificação do comportamento effectual por meio de ações individuais específicas (Fisher, 2012), é possível associar estas ações a metodologias de ensino em empreendedorismo identificadas por meio deste estudo.

Neste ponto, é importante ressaltar que a abordagem effectual não é melhor ou pior do que a abordagem causal ou demais abordagens existentes (Faia, Rosa, \& Machado, 2014), são apenas lógicas distintas de tomada de decisão, que se aplicam a diferentes contextos de forma simultânea, sobreposta ou intercalada, com vantagens e desvantagens associadas a cada uma delas (Read et al., 2011; Sarasvathy, 2001a, 2008). No entanto, e como visto anteriormente, o contraste dos fundamentos ontológicos e epistemológicos das duas abordagens gera a necessidade de se abordar o tema do empreendedorismo sob diferentes prismas, tanto em relação à análise teórica do fenômeno, quanto em relação ao ensino de empreendedorismo (Read, Song, \& Smit, 2009).

Assim, a análise das experiências em educação empreendedora com fundamento na teoria effectuation, em cinco instituições de ensino de quatro países diferentes, permite analisar como a teoria tem sido utilizada em sala de aula, o contexto em que ocorreram a estrutura dos cursos, seu design, formas de avaliação, metodologias de ensino utilizadas e percepção dos docentes sobre as experiências. Ato contínuo, o estudo categoriza as metodologias de ensino em função dos comportamentos effectuais definidos por Fisher (2012) e as dimensões do construto validadas por Chandler et al. (2011), além de identificar, ainda que preliminarmente, a influência da teoria effectuation sobre a intenção de empreender e a necessidade de se incorporar na literatura temáticas associadas aos antecedentes individuais.

\section{Metodologia}

O estudo utiliza-se de abordagem qualitativa (Yin, 2001) com perspectiva temporal de corte transversal e retrospectiva, por meio do método do estudo de casos múltiplos.

O nível da análise é multinível, pois a unidade de análise é composta tanto pelos indivíduos que participaram das experiências em educação empreendedora, ou seja, docentes e alunos, quanto pelas instituições em que as experiências ocorreram, com vistas a identificar o contexto organizacional nos quais as experiências se inserem. A seleção dos casos é não amostral, sendo obtida a partir de registros no site effectuation.org, que reúne experiências de ensino focadas em effectuation ao redor do mundo. Os casos analisados são apresentados na Tabela 1, que traz as principais informações sobre os casos analisados. 
Tabela 1

Experiências em Educação Empreendedora (EEE) - Teoria Effectuation

\begin{tabular}{|c|c|c|c|c|c|c|}
\hline Caso & Status acadêmicos & Escola & Universidade & País & Experiência & $\begin{array}{l}\text { Informações } \\
\text { adicionais }\end{array}$ \\
\hline C1 & $\begin{array}{l}\text { Professor e } \\
\text { Pesquisador em } \\
\text { Administração e } \\
\text { Empreendedorismo }\end{array}$ & $\begin{array}{l}\text { Escola de } \\
\text { Negócios de } \\
\text { Darden }\end{array}$ & $\begin{array}{l}\text { Universidade da } \\
\text { Virginia } \\
\text { (2a universidade } \\
\text { pública dos } \\
\text { EUA pelo } \\
\text { ranking US } \\
\text { News and } \\
\text { World Report) }\end{array}$ & $\begin{array}{l}\text { Estados } \\
\text { Unidos }\end{array}$ & Effectuation.org & $\begin{array}{l}\text { Criador da teoria } \\
\text { effectuation } \\
\text { Principal } \\
\text { acadêmico da área } \\
\text { Experiência } \\
\text { abrangente em } \\
\text { docência com } \\
\text { fundamento na } \\
\text { teoria effectuation }\end{array}$ \\
\hline $\mathrm{C2}$ & $\begin{array}{l}\text { Professor } \\
\text { Assistente de } \\
\text { Administração }\end{array}$ & $\begin{array}{l}\text { ETSIA } \\
\text { Aeronáuticos } \\
\text { da Escola } \\
\text { Politécnica de } \\
\text { Madri }\end{array}$ & $\begin{array}{l}\text { Universidade de } \\
\text { Madri } \\
\text { (Melhor escola } \\
\text { técnica da } \\
\text { Espanha pelo } \\
\text { ranking da } \\
\text { revista El } \\
\text { Mundo) }\end{array}$ & Espanha & $\begin{array}{l}\text { Hands-on Rapid } \\
\text { Innovation }\end{array}$ & $\begin{array}{l}\text { Experiência em } \\
\text { escola técnica de } \\
\text { universidade } \\
\text { pública } \\
\text { Experiência em } \\
\text { contexto de crise }\end{array}$ \\
\hline $\mathrm{C3}$ & $\begin{array}{l}\text { Professor } \\
\text { Assistente de } \\
\text { Estratégia e } \\
\text { Empreendedorismo }\end{array}$ & $\begin{array}{l}\text { Escola de } \\
\text { Administração } \\
\text { de Empresas } \\
\text { de Rotterdam }\end{array}$ & $\begin{array}{l}\text { Universidade } \\
\text { Erasmus de } \\
\text { Rotterdam } \\
\text { ( } 73^{\mathrm{a}} \\
\text { universidade do } \\
\text { mundo pelo } \\
\text { ranking do } \\
\text { Financial } \\
\text { Times) }\end{array}$ & Holanda & $\begin{array}{l}\text { Começando um } \\
\text { Negócio: Uma } \\
\text { Abordagem } \\
\text { Effectual }\end{array}$ & $\begin{array}{l}\text { Foco de atuação } \\
\text { corporativo } \\
\text { Introdução recente } \\
\text { de metodologia } \\
\text { com fundamento } \\
\text { na teoria } \\
\text { effectuation } \\
\text { Aumento do } \\
\text { interesse dos } \\
\text { alunos }\end{array}$ \\
\hline C4 & $\begin{array}{l}\text { Professor } \\
\text { Assistente de } \\
\text { Administração }\end{array}$ & $\begin{array}{l}\text { Leeds Escola } \\
\text { de Negócios }\end{array}$ & $\begin{array}{l}\text { Universidade de } \\
\text { Colorado em } \\
\text { Boulder } \\
\left(97^{\mathrm{a}}\right. \\
\text { universidade do } \\
\text { mundo pelo } \\
\text { ranking do } \\
\text { Financial } \\
\text { Times) }\end{array}$ & $\begin{array}{l}\text { Estados } \\
\text { Unidos }\end{array}$ & $\begin{array}{l}\text { Introdução ao } \\
\text { Empreendedorismo }\end{array}$ & $\begin{array}{l}\text { Relação com a } \\
\text { área ambiental } \\
\text { Contexto } \\
\text { organizacional e } \\
\text { utilização de } \\
\text { metodologia } \\
\text { inovadora } \\
\text { Pesquisador em } \\
\text { ascensão na área }\end{array}$ \\
\hline $\mathrm{C5}$ & $\begin{array}{l}\text { Professor } \\
\text { Assistente de } \\
\text { Administração }\end{array}$ & $\begin{array}{l}\text { ESSEC } \\
\text { Escola de } \\
\text { Negócios }\end{array}$ & $\begin{array}{l}\text { ESSEC Escola } \\
\text { de Negócios } \\
\text { ( } 8^{\text {a }} \text { escola de } \\
\text { negócios da } \\
\text { Europa pelo } \\
\text { ranking } \\
\text { Financial } \\
\text { Times })\end{array}$ & França & $\begin{array}{l}\text { Escrevendo o } \\
\text { Plano de Negócios }\end{array}$ & $\begin{array}{l}\text { Relação com } \\
\text { empreendedorismo } \\
\text { social } \\
\text { Experiência com } \\
\text { alunos de MBA } \\
\text { internacional } \\
\text { Utilização de } \\
\text { metodologia } \\
\text { multimídia }\end{array}$ \\
\hline
\end{tabular}

Nota. Fonte: elaborado pelos autores. 
O processo de escolha dos casos foi realizado em duas etapas. Na primeira etapa, foi criada uma base de dados com informações sobre docentes que atuam na área obtida por meio do site effectuation.org, de pesquisas realizadas no Google e do referencial teórico, tendo-se chegado a 18 experiências. Na segunda etapa, foram realizados os contatos, com o envio da carta de convite e as informações de contato dos pesquisadores. O roteiro de entrevista e a tecnologia utilizada para a realização das entrevistas (Skype e iPhone) foram testados e validados com o primeiro docente entrevistado.

A primeira entrevista permitiu identificar a necessidade de ajustes no roteiro de pesquisa e validar positivamente o Skype e o sistema de gravação como viáveis para o prosseguimento do estudo. Das 18 experiências identificadas na primeira etapa do processo de seleção dos casos, não foi possível localizar o contato do docente responsável por uma delas. Das 17 experiências restantes, 14 docentes responderam ao convite, sendo seis respostas positivas, oito negativas e três docentes não responderam. Uma das respostas positivas foi descartada pela indisponibilidade posterior do docente, chegando-se ao número final de cinco docentes entrevistados.

Como mencionado anteriormente, uma das características mais relevantes dos estudos de caso são as variadas formas de coletas de dados que permitem ser trianguladas para melhor validação dos resultados. Foram realizadas entrevistas semiestruturadas com questões abertas que permitissem flexibilidade à coleta de dados. As entrevistas permitiram emergir dados novos e variáveis não previstas no desenho inicial da pesquisa. As entrevistas foram realizadas pelo Skype e gravadas com autorização dos participantes. As entrevistas gravadas foram então transcritas, codificadas e classificadas para as análises, utilizando-se o software Atlas TI para facilitar a categorização das variáveis. A duração das entrevistas foi de, em média, 30 minutos, e as transcrições totalizaram aproximadamente 50 laudas. Tendo em vista as limitações impostas pelas políticas de governança das instituições pesquisadas, o acesso direto aos estudantes por meio do contato feito com os professores não foi autorizado. No entanto, documentos e informações em formato multimídia foram disponibilizados com vistas à compreensão da percepção dos alunos sobre as experiências vivenciadas.

Foi realizada observação indireta por meio de arquivos multimídia disponíveis na internet sobre as experiências em educação empreendedora analisadas. Informações relativas ao ambiente em sala de aula não foram consideradas relevantes ao escopo deste estudo, tendo em vista que o locus de ensino ou aprendizado das experiências analisadas ocorre em grande parte fora das salas de aulas por meio da interação dos alunos com o mundo real. Dados secundários como manuais sobre os cursos nos quais ocorrem as experiências, releases sobre atividades dos alunos e das disciplinas analisadas, informações sobre as instituições e, principalmente, a internet por meio do acesso a sites e demais recursos foram usados como fontes importantes de levantamento de dados.

As categorias desenvolvidas no Atlas TI tiveram incialmente um caráter descritivo e tiveram como fundamento o roteiro de entrevistas. A partir da análise inicial, foi possível separar as categorias iniciais com fundamento nos objetivos específicos da pesquisa, que culminaram nas análises finais do estudo, e especificamente na análise da consistência das metodologias de ensino utilizadas para o ensino com fundamento na teoria effectuation. A codificação aberta realizada durante o processo de análise permitiu as inferências a respeito da relação entre a teoria e intenção de empreender, cultura e educação formal dos alunos. A categorização das metodologias de ensino também permitiu a identificação das metodologias emergentes na área e a associação com as dimensões e comportamentos effectuais, mas sem a possibilidade de aprofundamento quanto às práticas específicas de aplicação em sala de aula em função da característica transversal e retrospectiva do estudo. 


\section{Resultados}

As experiências utilizadas no estudo preenchem os requisitos exigidos para experiências em educação empreendedora de Rideout e Gray (2013), que estabelece a necessidade de as experiências serem cursos regulares ou atividades extracurriculares, que possuam como objetivo ensinar empreendedorismo com fundamento na teoria effectuation, e que ocorram no contexto universitário ou de instituições de ensino superior. A diversidade dos casos permite compreender de forma abrangente o fenômeno objeto de estudo e analisar de maneira compreensiva as experiências em educação empreendedora ocorridas em cinco escolas de quatro países diferentes: Estados Unidos (2), Holanda (1), França (1) e Espanha (1). A seguir, são apresentados os principais resultados da pesquisa, segundo os objetivos específicos inicialmente definidos.

\section{Contexto em que ocorrem as experiências em educação empreendedora fundamentadas na teoria effectuation}

Observa-se que as universidades e escolas de negócios onde as experiências ocorreram são consideradas instituições de ensino de excelência em relação à produção acadêmica, acreditações, estrutura, recursos financeiros e posições em rankings de qualidade. Das cinco experiências analisadas, quatro ocorreram em escolas de negócios e apenas uma ocorreu em uma escola politécnica para alunos de engenharia. Mesmo as ocorridas em escolas de negócios, as disciplinas são ministradas para alunos da graduação que não são do curso de administração, o que evidencia a abrangência das disciplinas nas instituições pesquisadas.

A mesma diversidade, entretanto, não pode ser atribuída aos docentes, pois os cinco docentes entrevistados na pesquisa pertencem ao departamento de gestão de suas respectivas escolas. Dos cinco docentes entrevistados, dois docentes possuem título de mestre e os demais possuem o título de doutor ou PhD. A área de formação dos docentes é variada e abrange desde engenharia a jornalismo, mas todos possuem pós-graduação (mestrado ou doutorado) em administração. Quatro das cinco experiências analisadas utilizam o inglês como idioma oficial e apenas uma tem partes do curso no idioma espanhol, mas toda a leitura e ferramentas apresentadas durante o curso são em inglês.

\section{Estrutura dos cursos com fundamento na teoria effectuation}

A análise dos resultados referentes aos objetivos, design e formas de avaliação dos cursos permite responder ao segundo objetivo específico da pesquisa que se relaciona à estrutura dos cursos. O tempo de duração das experiências é amplo e varia de um dia no contexto de educação executiva, até cursos de quinze semanas para alunos de graduação. A estrutura dos cursos varia conforme o tempo, os objetivos de aprendizado e o público-alvo a quem se destina, e nos casos analisados não foram identificados padrões em relação à forma como os cursos são estruturados. Há, no entanto, uma característica que permeia todas as experiências em educação empreendedora, objeto da pesquisa, e que deve orientar sua estruturação, qual seja, a prática do modelo dinâmico da teoria effectuation. Sarasvathy (2008) salienta que a introdução do modelo dinâmico é um dos pontos mais importantes para o ensino do empreendedorismo sob a lógica effectual e que sua apresentação deve ser feita não apenas conceitualmente, mas de forma contextualizada com um caso ou uma ideia de negócio que ilustre seu funcionamento. Para a teoria effectuation, o aprendizado ocorre quando o aluno pratica o processo dinâmico com vistas à identificação de oportunidade com base em recursos disponíveis e ao desenvolvimento de sua rede de relacionamento. É por isso que o resultado da análise permite identificar semelhanças entre as experiências no que se refere ao locus de ensino ou aprendizado, pois nos casos analisados o ambiente de aprendizado se inicia em sala de aula, onde o docente apresenta os conceitos e pressupostos da teoria, mas se desenvolve no mundo real à medida que os alunos agem sobre oportunidades e interagem com stakeholders. A Tabela 2 apresenta as informações a respeito do design, público-alvo e contribuição dos cursos, analisados a seguir. 
Tabela 2

Design, Público-Alvo e Contribuição das Experiências

\begin{tabular}{|c|c|c|c|c|}
\hline Caso & Experiência & Design & Público-alvo & Contribuição \\
\hline C1 & Effectuation.org & $\begin{array}{l}20 \text { Aulas (livro-texto) } \\
\text { Curso regular de } 1 \text { bimestre } \\
\text { Curso regular de } 1 \text { semestre } \\
\text { Curso de } 1 \text { semana } \\
\text { Seminário de } 1 \text { ou } 2 \text { dias } \\
\text { Workshops e outros }\end{array}$ & $\begin{array}{l}\text { Graduação e pós- } \\
\text { graduação, } \\
\text { doutorado, MBA, } \\
\text { graduação, ensino } \\
\text { fundamental, } \\
\text { gestores públicos, } \\
\text { etc. }\end{array}$ & $\begin{array}{l}\text { Superação das objeções que as } \\
\text { pessoas utilizam para não se } \\
\text { tornar um empreendedor } \\
\text { Experimentar o processo de } \\
\text { criação de novos negócios } \\
\text { Decidir sobre potencial e } \\
\text { interesse em se tornar } \\
\text { empreendedor } \\
\text { Compreensão sobre o universo } \\
\text { empreendedor }\end{array}$ \\
\hline $\mathrm{C2}$ & $\begin{array}{l}\text { Hands-on Rapid } \\
\text { Innovation }\end{array}$ & $\begin{array}{l}\text { Curso de } 3 \text { meses } \\
\text { (teoria e dinâmica em } \\
\text { workshop de } 1 \text { dia) }\end{array}$ & $\begin{array}{l}\text { Graduação } \\
\text { (engenharia) }\end{array}$ & $\begin{array}{l}\text { Introdução ao } \\
\text { empreendedorismo } \\
\text { Aumento da consciência sobre } \\
\text { o tema }\end{array}$ \\
\hline $\mathbf{C 3}$ & $\begin{array}{l}\text { Começando um } \\
\text { Negócio: Uma } \\
\text { Abordagem } \\
\text { Effectual }\end{array}$ & Curso regular de 1 trimestre & $\begin{array}{l}\text { Graduação } \\
\text { (todos os cursos) }\end{array}$ & $\begin{array}{l}\text { Ação sobre uma oportunidade } \\
\text { de negócios }\end{array}$ \\
\hline C4 & $\begin{array}{l}\text { Introdução ao } \\
\text { Empreendedo- } \\
\text { rismo }\end{array}$ & $\begin{array}{l}\text { Curso regulares de } 1 \text { semestre } \\
\text { - } 29 \text { sessões em } 4 \text { meses de } \\
\text { aula }\end{array}$ & $\begin{array}{l}\text { Graduação } \\
\text { (exceto gestão de } \\
\text { negócios) }\end{array}$ & $\begin{array}{l}\text { Avaliação sobre potencial e } \\
\text { interesse em se tornar } \\
\text { empreendedor } \\
\text { Prática do processo } \\
\text { empreendedor (effectual) }\end{array}$ \\
\hline C5 & $\begin{array}{l}\text { Escrevendo o } \\
\text { Plano de } \\
\text { Negócios }\end{array}$ & $\begin{array}{l}\text { Curso regular de } 10 \text { sessões } \\
\text { de } 2 \mathrm{~h} 30 \mathrm{~min} \text { cada }\end{array}$ & MBA Global & $\begin{array}{l}\text { Integração dos elementos do } \\
\text { plano e do modelo de negócios } \\
\text { Função e limitações do plano } \\
\text { de negócios } \\
\text { Desenvolvimento de uma ideia } \\
\text { de negócios }\end{array}$ \\
\hline
\end{tabular}

Nota. Fonte: elaborado pelos autores.

A declaração de objetivos das disciplinas observadas corrobora os resultados referentes à estrutura dos cursos, visto que, em todos os casos, faz-se menção à necessidade de agir ou de se praticar o modelo dinâmico effectual. O resultado da análise dos casos permite identificar dois tipos diferentes de objetivos ilustrados na Tabela 2: um objetivo primário, que é encontrado em todas as experiências e que se refere à prática do modelo, e objetivos secundários, que por sua vez buscam adequar as disciplinas ao seu contexto e aos diferentes públicos-alvo.

A análise das formas de avaliação identificadas nos casos permite concluir que a avaliação é feita em duas esferas, uma individual e outra em grupo. Por se tratar de disciplinas experienciais e que possuem como um de seus pilares o desenvolvimento de uma rede de relacionamentos, o exercício prático é muito importante para gerar aprendizado por meio da experiência, e o processo de desenvolvimento das ideias ou negócios é o elemento central do processo de avaliação. O percentual da nota individual e do trabalho em grupo difere entre os casos, mas é possível identificar que a prática do modelo dinâmico é o principal foco dos processos de avaliação em grupo e, na esfera individual, enfocase a reflexão sobre a prática durante o desenvolvimento do projeto. A Tabela 3 apresenta as formas de avaliação utilizadas nos casos analisados. 
Tabela 3

Formas de Avaliação

\begin{tabular}{lll}
\hline Caso & Experiência & Formas de avaliação \\
\hline C1 & Effectuation.org & i. Relatório sobre desenvolvimento do negócio \\
& & i. Obter ao menos três compromissos com stakeholders \\
& & g. Uso da teoria para iniciar um negócio \\
\hline C2 & Hands-on Rapid Innovation & i. Autoavaliação (30\%) \\
& & g. Relatório dos projetos com a utilização de um blog (40\%) \\
& & g. Apresentações semanais sobre o desenvolvimento dos projetos (30\%) \\
\hline C3 & Começando um Negócio: & i. Relatório final sobre aprendizado e desenvolvimento do negócio \\
& Uma Abordagem Effectual & g. Apresentação em pitch \\
& & g. Conteúdo dos projetos (teorias) \\
\hline C4 & Introdução ao & i. Dinheiro acumulado (10\%) \\
& Empreendedorismo & i. Perguntas e respostas (20\%) \\
& & i. Participação em sala (20\%) \\
& & i. Avaliação pelo grupo (10\%) \\
& & g. Oito desafios reais (40\%) \\
\hline C5 & Escrevendo o & i. Aprendizado individual (10\%) \\
& Plano de Negócios & g. Avaliação do júri (40\%) \\
& & g. Progresso dos projetos (30\%) \\
& g. Participação (20\%)
\end{tabular}

Nota. A sigla i na tabela se refere à avaliação individual e a sigla g se refere à avaliação em grupo. Fonte: elaborado pelos autores.

Em todos os casos há critérios individuais e coletivos sendo avaliados e a ênfase é dada ao processo de desenvolvimento da ideia ou do negócio em si, por meio da prática do modelo dinâmico da teoria com vistas à obtenção de comprometimento dos stakeholders e utilização dos recursos disponíveis pelos alunos.

\section{Metodologias utilizadas para ensino de empreendedorismo com fundamento na teoria effectuation}

O terceiro objetivo específico da pesquisa refere-se ao mapeamento das metodologias de ensino, que foi feito em diferentes etapas. Em primeiro lugar, foi feita a análise do caso $1 \mathrm{com}$ foco no material do effectuation.org. Em seguida, identificaram-se as metodologias utilizadas nos demais casos de ensino em empreendedorismo. Ato contínuo, as metodologias indicadas pela teoria (Neck \& Greene, 2011; Solomon, Duffy, \& Tarabishy, 2002) foram confrontadas com as identificadas nos casos analisados para obtenção de uma lista completa das metodologias. A Tabela 4 resume as metodologias identificadas nos casos objeto deste trabalho. Considerando-se a totalidade de metodologias, foram identificadas vinte e oito metodologias distintas nos casos analisados. As metodologias de ensino com fundamento na teoria se relacionam à compreensão e prática do modelo dinâmico como elemento integrador. Nesse sentido, o objetivo das metodologias de ensino associadas à teoria effectuation é identificar recursos disponíveis e desenvolver uma rede de relacionamento a partir da qual é possível obter compromisso dos stakeholders. As metodologias dão suporte à compreensão do modelo e visam desenvolver as habilidades necessárias para sua aplicação prática no mundo real. Nesse contexto, metodologias 
relacionadas com o teste de hipóteses de Ries (2011), modelagem de negócios de Osterwalder e Pigneur (2010) e desenvolvimento de clientes de Blank e Dorf (2012) não estão relacionadas diretamente à teoria effectuation, mas aparecem como metodologias complementares que permitem aos alunos o exercício de elementos do modelo effectual. É possível notar que metodologias tradicionais são utilizadas em conjunto com metodologias e temas emergentes e, em muitos casos, há o desenvolvimento de dinâmicas diferenciadas e a utilização de tecnologias inovadoras.

Tabela 4

Principais Metodologias de Ensino

\begin{tabular}{|c|c|c|c|}
\hline Caso & Escola & Experiência & Metodologias de ensino \\
\hline C1 & $\begin{array}{l}\text { Darden Escola de } \\
\text { Negócios }\end{array}$ & Effectuation.org & $\begin{array}{l}\text { 1. Aulas expositivas } \\
\text { 2. Estudos de caso } \\
\text { 3. Coaching (mentores) } \\
\text { 4. Criatividade } \\
\text { 5. Simulação (role playing) } \\
\text { 6. Dinâmica urnas, venda, jantar } \\
\text { 7. Jogos \& simulação } \\
\text { 8. Ferramentas de diagnóstico } \\
\text { 9. Vídeos } \\
\text { 10. Livro-texto } \\
\text { 11. Palestrantes convidados } \\
\text { 12. Ferramenta multimídia (site) } \\
\text { 13. Negociação (equity) }\end{array}$ \\
\hline $\mathrm{C2}$ & $\begin{array}{l}\text { Escola } \\
\text { Politécnica de } \\
\text { Madri }\end{array}$ & $\begin{array}{l}\text { Hands-on Rapid } \\
\text { Innovation }\end{array}$ & $\begin{array}{l}\text { 1. Aulas expositivas } \\
\text { 2. Estudos de caso } \\
\text { 3. Dinâmica A taste } \\
\text { 4. Coaching (mentores) } \\
\text { 5. Pitch (storytelling) } \\
\text { 6. Mídia social (blog) }\end{array}$ \\
\hline $\mathbf{C 3}$ & $\begin{array}{l}\text { Escola de } \\
\text { Administração de } \\
\text { Empresas de } \\
\text { Rotterdam }\end{array}$ & $\begin{array}{l}\text { Começando um } \\
\text { Negócio: } \\
\text { Uma Abordagem } \\
\text { Effectual }\end{array}$ & $\begin{array}{l}\text { 1. Aulas expositivas } \\
\text { 2. Estudos de caso } \\
\text { 3. Coaching (mentores) } \\
\text { 4. Pitch (storytelling) } \\
\text { 5. Desenvolvimento de clientes } \\
\text { 6. Design thinking } \\
\text { 7. Reflexão sobre a prática } \\
\text { 8. Modelo de negócios } \\
\text { 9. Teste de hipóteses }\end{array}$ \\
\hline
\end{tabular}


Tabela 4 (continuação)

\begin{tabular}{|c|c|c|c|}
\hline Caso & Escola & Experiência & Metodologias de ensino \\
\hline \multirow[t]{15}{*}{ C4 } & \multirow{15}{*}{$\begin{array}{l}\text { Leeds Escola de } \\
\text { Negócios }\end{array}$} & \multirow{15}{*}{$\begin{array}{l}\text { Introdução ao } \\
\text { Empreendedorismo }\end{array}$} & 1. Desafios reais \\
\hline & & & 2. Aulas expositivas \\
\hline & & & 3. Coaching (mentores) \\
\hline & & & 4. Pitch (storytelling) \\
\hline & & & 5. Abertura de empresa \\
\hline & & & 6. Negociação (equity) \\
\hline & & & 7. Teste de hipóteses \\
\hline & & & 8. Dinâmica 2 horas \\
\hline & & & 9. Modelo de negócios \\
\hline & & & 10. Reflexão sobre a prática \\
\hline & & & 11. Ferramentas de diagnóstico \\
\hline & & & 12. Livro-texto \\
\hline & & & 1. Desafios reais \\
\hline & & & 2. Aulas expositivas \\
\hline & & & 3. Coaching (mentores) \\
\hline \multirow[t]{10}{*}{$\mathrm{C5}$} & \multirow{10}{*}{$\begin{array}{l}\text { ESSEC Escola de } \\
\text { Negócios }\end{array}$} & \multirow{10}{*}{$\begin{array}{l}\text { Escrevendo o } \\
\text { Plano de Negócios }\end{array}$} & 1. Aulas expositivas \\
\hline & & & 2. Plano de negócios \\
\hline & & & 3. Modelo de negócios \\
\hline & & & 4. Ferramentas de diagnóstico \\
\hline & & & 5. Teste de hipóteses \\
\hline & & & 6. Coaching (mentores) \\
\hline & & & 7. Consultoria com empreendedores \\
\hline & & & 8. Reflexão sobre a prática \\
\hline & & & 9. Viagem a campo \\
\hline & & & 10. Ferramenta multimídia (site) \\
\hline
\end{tabular}

Nota. Fonte: elaborado pelos autores.

\section{Percepções dos docentes sobre as experiências em educação empreendedora com fundamento na teoria effectuation}

Os resultados deste item não pretendem exaurir as respostas possíveis ao quarto objetivo específico do estudo, mas apresentar um primeiro contato com o fenômeno com vistas à compreensão do uso da teoria effectuation no ensino de empreendedorismo.

\section{Teoria effectuation e intenção de empreender}

A partir da análise dos dados, foram identificados indícios no sentido de que a teoria effectuation influencia a intenção dos alunos em empreender. Nas palavras do professor C1: "o que acontece é que os alunos ficam mais abertos a tentar ...; o número de alunos começando seus próprios negócios após eles terem terminado o curso tem aumentado bastante". 
No entanto, as evidências do efeito da experiência em educação empreendedora sobre intenção de empreender não são uníssonas. Para o professor C3, o efeito da teoria sobre a intenção de empreender é "irrelevante, mas bom se os alunos se tornarem empreendedores. Ter um perfil empreendedor é a essência aqui”. Para o professor C5, a intenção pode aumentar apenas no grupo de alunos que já identificou, por meio da teoria, que tem os recursos necessários para tanto. Já o professor C4 afirma:

"Eu não diria que os alunos se tornam mais propensos a empreender. Eu acho que o resultado é que eles agora têm uma abordagem que não exige que eles fiquem longas e tediosas horas escrevendo um plano de negócios, mas sim que possam se engajar em pequenas experiências para teste de suas hipóteses e, assim, chegar ao mercado mais rapidamente".

Por isso, a relação entre teoria effectuation e intenção de empreender precisa ser testada a partir de pesquisa que utilize metodologia adequada para sua aferição. De acordo com a teoria effectuation (Sarasvathy, 2001a, 2001b, 2008), a utilização de seus princípios e pressupostos muda o critério utilizado para a tomada de decisão de empreender, o que aumenta a intenção do indivíduo em fazê-lo. O fundamento teórico que sustenta essa proposição possui duas premissas, a primeira no sentido de identificar se esses indivíduos já possuem a intenção, e a segunda no sentido de verificar se esses indivíduos não empreendem em função dos argumentos elencados pela teoria, quais sejam: (a) não ter uma boa ideia, (b) não ter recursos suficientes, (c) não saber o que fazer ou (d) ter medo de fracassar (Read et al., 2011).

A análise dos casos permitiu a identificação de dois tipos de pessoas, as pessoas que não têm intenção de empreender e as pessoas que têm intenção de empreender. Para o caso das pessoas que não possuem intenção de empreender, não há evidências da influência da teoria na intenção de empreender, mas para as que pretendem empreender, independentemente da motivação ou situação, há evidências no sentido de que a teoria influencia positivamente sua intenção.

\section{Teoria effectuation e cultura}

Outro aspecto evidenciado durante a análise dos dados refere-se à influência da cultura na intenção de empreender. O interesse pelo assunto surgiu do argumento existente no livro de Read, Sarasvathy, Dew, Wiltbank e Ohlsson (2011) no sentido de que as pessoas não sabem como tomar a decisão de empreender, e que as razões disso podem estar relacionadas a questões culturais ou características próprias do indivíduo. Adicionalmente, a experiência com alunos de engenharia em uma universidade pública na Espanha resultou em evidências sobre a influência da cultura na receptividade e aumento da intenção de empreender dos alunos que vivenciaram a experiência naquele país. Alguns trechos evidenciam a questão cultural como inibidora da intenção dos alunos em empreender, mas há evidências também no sentido contrário. Conforme afirmou o professor C3, "effectuation é tão fundamental em sua abordagem que vai além das diferenças culturais". Para o professor C4, "eu acho que [o empreendedorismo] é mais relacionado com a personalidade do que com um tipo de país ou traço cultural". Nesta mesma linha, o professor C1 relata:

"Quando as pessoas levantam uma objeção cultural, sou capaz de lhes responder que a ideia é começar com as coisas que funcionam com sua cultura ..., mostro para elas como empreendedores na cultura delas criaram grandes empresas utilizando os princípios da teoria effectuation".

Face às evidências, conclui-se que fatores culturais podem influenciar a experiência em educação empreendedora com fundamento na teoria effectuation antes do contato do aluno com a teoria, mas não devem prevalecer após a compreensão de seus conceitos e princípios.

\section{A teoria effectuation e educação formal}

As evidências no que se refere à influência da cultura fizeram emergir, dos casos estudados, dados sobre diferenças em relação à educação formal dos alunos como causa da diferença entre indivíduos na adoção da teoria effectuation. Pondera-se, nesse sentido, que a educação formal certamente influencia a forma como os alunos se relacionam com o seu contexto. Nas palavras do professor C1: "estudantes de 
engenharia tendem a ser muito mais causais e estruturados e eles odeiam a ideia de sair da sala e efetivamente trabalhar com pessoas, a ideia de que outras pessoas vão influenciar suas visões". Da mesma forma, o professor C4 afirma:

"Eu tenho estudantes de engenharia que estão acostumados com orientações rígidas e clareza de propósitos, e com respostas do tipo certo e errado. Eles vêm a mim e dizem que isso é horrível, que é muito louco, que tudo é muito incerto. Nesses casos eu geralmente digo ... bem isso é estar no lado do empreendedor, você está descobrindo que talvez isso não seja para você e isso é absolutamente normal".

No entanto, o professor C5 não vê uma relação direta entre educação formal e empreendedorismo: "vejo engenheiros que querem se tornar empreendedores, mas também vejo que eles querem ir para a área de finanças ..., não há padrão com relação à formação que as pessoas têm".

Infere-se, dessa forma, que a educação formal do indivíduo parece influenciar o seu processo de aprendizagem, que também deve levar em conta outros aspectos referentes a experiências prévias, carreira profissional, entre outros. De fato, não se pode negar que a formação do indivíduo e seus antecedentes pessoais tenham influência sobre a forma como se relaciona com o mundo. Não há, no entanto, um padrão que possa determinar a direção dessa influência, motivo pelo qual se infere que a relação da formação é moderadora do fenômeno e a ela não pode ser atribuída uma direção específica. É importante ressaltar nesse momento que a utilização pelos alunos da lógica causal e da lógica effectual para a tomada de decisão é indissociável, havendo prevalência no uso de uma ou de outra dependendo das características do indivíduo e das características do ambiente.

\section{Categorização das metodologias de ensino em função das dimensões e comportamentos associados à teoria effectuation}

O esforço de categorização das metodologias de ensino identificadas nos casos em função das dimensões (Chandler et al., 2011) e comportamentos (Fisher, 2012) associados à teoria effectuation contribui ao desenvolvimento do tema, à medida que estabelece uma relação objetiva entre a metodologia e a ação individual que se pretende desenvolver. Conforme mencionado anteriormente, foram identificadas vinte e oito metodologias de ensino, que visam desenvolver as habilidades empreendedoras de maneira geral. Algumas são necessárias para a aplicação da teoria effectuation no mundo real, mas outras se fundamentam na lógica causal, motivo pelo qual metodologias emergentes aparecem lado a lado de metodologias tradicionais de ensino em empreendedorismo. Isso significa que, de fato, a lógica effectual e causal são alternativas e, em alguns casos, complementares, sendo exploradas e utilizadas de maneira simultânea, sobreposta ou intercalada, dependendo do contexto. A Tabela 5 apresenta a categorização das metodologias identificadas nos casos objeto deste trabalho. 
Tabela 5

Metodologias de Ensino em Função dos Comportamentos e Dimensões Effectuais

\begin{tabular}{|c|c|c|c|}
\hline $\begin{array}{l}\text { Dimensões de } \\
\text { Sarasvathy (2001a) }\end{array}$ & Chandler et al. (2011) & Fisher (2012) & Metodologias de Ensino \\
\hline Experimentação & $\begin{array}{l}\text { Nós experimentamos diferentes produtos e/ou } \\
\text { modelos de negócios. } \\
\text { O produto/serviço que fornecem agora é } \\
\text { essencialmente o mesmo que originalmente } \\
\text { conceituado. } \\
\text { O produto/serviço que fornecem agora é } \\
\text { substancialmente diferente do que primeiro } \\
\text { imaginou. } \\
\text { Nós tentamos diferentes abordagens até } \\
\text { encontrar um modelo de negócio que funcione. }\end{array}$ & $\begin{array}{l}\text { 1. Desenvolve diversas variações de um } \\
\text { produto ou serviço para chegar a uma oferta } \\
\text { comercial: Criação de vários protótipos } \\
\text { diferentes/Entrega diferentes serviços no } \\
\text { processo de identificação da oferta. } \\
\text { 2. Experimenta diferentes maneiras de vender } \\
\text { e/ou entregar um produto ou serviço: Uso de } \\
\text { diferentes canais de distribuição/Uso de } \\
\text { diferentes modelos de receita. } \\
\text { 3. Altera o produto ou serviço } \\
\text { substancialmente enquanto o negócio se } \\
\text { desenvolve. }\end{array}$ & $\begin{array}{l}\text { 1. Aulas expositivas } \\
\text { 2. Livro-texto } \\
\text { 3. Estudos de caso } \\
\text { 4. Vídeos } \\
\text { 5. Reflexão sobre a prática } \\
\text { 6. Ferramenta multimídia (site) } \\
\text { 7. Coaching (mentores) } \\
\text { 8. Criatividade } \\
\text { 9. Dinâmicas jantar, a taste e } 2 \text { horas } \\
\text { 10. Desafios reais } \\
\text { 11.Desenvolvimento de cliente } \\
\text { 12. Design thinking } \\
\text { 13. Teste de hipóteses } \\
\text { 14. Modelos de negócios }\end{array}$ \\
\hline Perda Suportável & $\begin{array}{l}\text { Tivemos o cuidado de não comprometer mais } \\
\text { recursos do que nós poderíamos perder. } \\
\text { Tivemos o cuidado para não arriscar mais } \\
\text { dinheiro do que estávamos dispostos a perder } \\
\text { com a nossa ideia inicial. } \\
\text { Tivemos o cuidado para não arriscar tanto } \\
\text { dinheiro que colocasse a empresa em risco } \\
\text { financeiro se as coisas não dessem certo. }\end{array}$ & $\begin{array}{l}\text { 1. Compromete apenas quantidades limitadas } \\
\text { de recursos para o negócio de cada vez: } \\
\text { Procura maneiras de fazer as coisas de forma } \\
\text { barata. } \\
\text { 2. Limita os recursos comprometidos para a } \\
\text { empresa com o que poderia ser perdido: } \\
\text { Desenvolve produto ou serviço utilizando apenas } \\
\text { recursos pessoais. }\end{array}$ & $\begin{array}{l}\text { 1. Aulas expositivas } \\
\text { 2. Livro-texto } \\
\text { 3. Estudos de caso } \\
\text { 4. Vídeos } \\
\text { 5. Reflexão sobre a prática } \\
\text { 6. Ferramenta multimídia (site) } \\
\text { 7. Coaching (mentores) } \\
\text { 8. Ferramentas de diagnóstico }\end{array}$ \\
\hline
\end{tabular}




\section{Tabela 5 (continuação)}

\begin{tabular}{|c|c|c|c|}
\hline $\begin{array}{l}\text { Dimensões de } \\
\text { Sarasvathy (2001a) }\end{array}$ & Chandler et al. (2011) & Fisher (2012) & Metodologias de Ensino \\
\hline Flexibilidade & $\begin{array}{l}\text { Nós permitimos a empresa evoluir à medida que } \\
\text { as oportunidades surgiram. } \\
\text { Nós adaptamos o que estávamos fazendo com os } \\
\text { recursos que tínhamos. } \\
\text { Nós éramos flexíveis e tiramos vantagens das } \\
\text { oportunidades conforme elas surgiram. } \\
\text { Temos evitado cursos de ação que restringiam a } \\
\text { nossa flexibilidade e adaptabilidade. }\end{array}$ & $\begin{array}{l}\text { 1. Responde a oportunidades não planejadas } \\
\text { que possam surgir: Rapidamente muda a oferta } \\
\text { ou o modelo de receita quando surgem novas } \\
\text { oportunidades. } \\
\text { 2. Adapta o que está sendo feito com os } \\
\text { recursos disponíveis: Concentra-se no que está } \\
\text { disponível ao decidir sobre uma estratégia de } \\
\text { ação. } \\
\text { 3. Evita cursos de ação que restringem a } \\
\text { flexibilidade e adaptabilidade: Consciente- } \\
\text { mente rejeita cursos de ação que irá } \\
\text { comprometê-los (relações ou investimentos). }\end{array}$ & $\begin{array}{l}\text { 1.Aulas expositivas } \\
\text { 2. Livro-texto } \\
\text { 3. Estudos de caso } \\
\text { 4. Vídeos } \\
\text { 5. Reflexão sobre a prática } \\
\text { 6. Ferramenta multimídia (site) } \\
\text { 7. Coaching (mentores) } \\
\text { 8. Teste de hipóteses } \\
\text { 9. Modelos de negócios }\end{array}$ \\
\hline Pré-acordos & $\begin{array}{l}\text { Nós usamos um número significativo de acordos } \\
\text { com clientes, fornecedores e outras organizações } \\
\text { e pessoas para reduzir a quantidade de incerteza. } \\
\text { Usamos pré-acordos de clientes e fornecedores o } \\
\text { mais rápido possível. }\end{array}$ & $\begin{array}{l}\text { 1. Faz acordos com clientes, fornecedores e } \\
\text { outras organizações: Negocia com terceiros } \\
\text { antes de ter um produto ou serviço totalmente } \\
\text { desenvolvido. }\end{array}$ & $\begin{array}{l}\text { 1. Aulas expositivas } \\
\text { 2. Livro-texto } \\
\text { 3. Estudos de caso } \\
\text { 4. Vídeos } \\
\text { 5. Reflexão sobre a prática } \\
\text { 6. Ferramenta multimídia (site) } \\
\text { 7. Coaching (mentores) } \\
\text { 8. Pitch (storytelling) } \\
\text { 9. Negociação (equity) }\end{array}$ \\
\hline
\end{tabular}

Nota. As metodologias de ensino em negrito são comuns às dimensões da teoria effectuation, enquanto as demais são específicas das dimensões a que estão relacionadas. Fonte: elaborado pelos autores. 
Nota-se que metodologias tradicionais coexistem com metodologias emergentes e que os comportamentos associados à teoria effectuation são específicos e, em alguns casos, não necessitam de metodologias diferentes das já existentes. Exemplo disso é o comportamento associado à dimensão préacordos, que se utiliza de metodologias existentes, porém com abordagem diferente da tradicional, tendo em vista que a negociação com stakeholders ocorre antes de o empreendedor possuir um produto ou serviço totalmente desenvolvido. Quanto às demais dimensões, identificou-se as metodologias relacionadas a teste de hipóteses (Ries, 2011), modelagem de negócios (Osterwalder \& Pigneur, 2010) e desenvolvimento de clientes (Blank \& Dorf, 2012) como fundamentais para o desenvolvimento dos comportamentos effectuais, mas sempre em complemento a metodologias tradicionais de ensino de empreendedorismo.

\section{Contribuições}

A partir dos resultados da análise dos casos estudados, o estudo faz três contribuições à literatura sobre empreendedorismo. Em primeiro lugar, o estudo analisa e compara casos de ensino em diferentes contextos e identifica que a utilização e prática do modelo dinâmico de effectuation é um elemento integrador do ensino de empreendedorismo com fundamento na teoria. $\mathrm{O}$ estudo faz isso por meio da comparação das características de cada um dos casos e da análise da estrutura, das formas de avaliação e principalmente do design das experiências de ensino objeto do estudo, que buscam desenvolver a expertise no que se refere à prática e aos pressupostos que permeiam e orientam a teoria effectuation.

Em segundo lugar, o estudo categoriza as metodologias de ensino em função dos comportamentos effectuais definidos por Fisher (2012) e as dimensões do construto validadas por Chandler et al. (2011). Os resultados da categorização são apresentados na Tabela 5 e permitiram identificar metodologias de ensino emergentes no campo do empreendedorismo, a exemplo do teste de hipóteses (Ries, 2011), modelagem de negócios (Osterwalder \& Pigneur, 2010) e desenvolvimento de clientes (Blank \& Dorf, 2012), em adição às metodologias salientadas nos estudos de Neck e Greene (2011) e Solomon, Duffy e Tarabishy (2002). Mas em que pese o consenso sobre a necessidade de novas metodologias de ensino, os resultados da análise de categorização proposta por este estudo também permitem concluir que as metodologias emergentes no campo são utilizadas em conjunto com metodologias tradicionais de ensino e que, no caso da dimensão pré-acordo, não há a necessidade de uma nova metodologia específica.

Em terceiro lugar, o estudo gera insights preliminares a respeito da influência da teoria effectuation sobre a intenção de empreender e a necessidade de se incorporar na literatura temáticas associadas aos antecedentes individuais. É esperado que a cultura em que o indivíduo está inserido e sua educação formal influenciem a forma como se comporta e vê o mundo. Por outro lado, o ensino de empreendedorismo pretende gerar resultados reais para o desenvolvimento econômico e social, o que ocorre por meio da criação e desenvolvimento de novos negócios. Desta forma, compreender como e se a teoria effectuation influencia a intenção de empreender é positiva no sentido de estimular ações e comportamentos empreendedores capazes de gerar os resultados almejados.

O estudo também faz contribuições potenciais à prática, ao permitir, em função da categorização realizada, que educadores utilizem metodologias de ensino adequadas ao desenvolvimento dos comportamentos effectuais específicos. A atenção aos antecedentes pessoais dos indivíduos que tenham contato com a teoria também pode potencializar os seus efeitos e o foco na prática é característica essencial para que os indivíduos adquiram experiência na utilização do modelo dinâmico de effectuation. Por fim, a reunião de experiências em diferentes contextos permite aos educadores uma compreensão abrangente do uso da teoria effectuation e serve como referência para o desenvolvimento de cursos regulares e atividades extracurriculares que utilizem a teoria no contexto das instituições de ensino superior. 


\section{Conclusão}

Desde a consolidação da importância do empreendedorismo surgiram inúmeras abordagens teóricas sobre o tema, com recente destaque para a teoria effectuation. A partir dos casos analisados no estudo, buscou-se identificar experiências em educação empreendedora com o objetivo de compreender como a teoria effectuation está sendo utilizada para ensinar empreendedorismo e categorizar as metodologias de ensino com fundamento nas dimensões e comportamentos a ela associados. A análise destaca o modelo dinâmico como elemento integrador dos casos e a utilização da lógica effectual como pressuposto para a aplicação de metodologias emergentes no ensino de empreendedorismo (Blank \& Dorf, 2012; Osterwalder \& Pigneur, 2010; Ries, 2011).

O estudo também sugere que a mudança dos pressupostos utilizados para tomada de decisão influencia a intenção de empreender e que é necessário que se atente aos antecedentes pessoais dos indivíduos, como a cultura e a educação formal. Finalmente, como limitação do trabalho, aponta-se o fato de que os alunos não foram entrevistados diretamente da mesma forma que os professores, tendose acesso apenas aos relatos disponibilizados em fontes secundárias. A limitação de espaço também permitiu apenas uma análise inicial da relação entre os comportamentos effectuais e as metodologias identificadas, sem que fosse possível analisar como as metodologias são utilizadas e quais são abordagens específicas utilizadas com o objetivo de desenvolver as ações individuais almejadas.

\section{Referências}

Alvarez, S. A., \& Barney, J. B. (2007). Discovery and creation: alternative theories of entrepreneurial action. Strategic Entrepreneurship Journal, 1(1/2), 11-26. doi: 10.1002/sej.4

Alvarez, S. A., \& Barney, J. B. (2013). Epistemology, opportunities, and entrepreneurship: comments on Venkataraman et al. (2012) and Shane (2012). Academy of Management Review, 38(1), 154157. doi: $10.5465 / \mathrm{amr} .2012 .0069$

Ansoff, I. (1965). Corporate strategy: an analytic approach to business policy for growth and expansion. New York, NY: McGraw- Hill.

Blank, S., \& Dorf, B. (2012). The startup owner's manual: the step-by-step guide for building a great company. Pescadero, CA: K\&S Ranch Publishing.

Chandler, G. N., DeTienne, D. R., McKelvie, A., \& Mumford, T. V. (2011). Causation and effectuation processes: a validation study. Journal of Business Venturing, 26(3), 375-390. doi: 10.1111/j.1540-6520.2012.00537.x

Christensen, C. M., \& Carlile, P. R. (2009). Course research:using the case method to build and teach management theory. Academy of Management Learning \& Education, 8(2), 240-251. doi: 10.5465/AMLE.2009.41788846

DeTienne, D., \& Chandler, G. (2004). Opportunity identification and its role in the entrepreneurial classroom: a pedagogical approach and empirical test. Academy of Management Learning and Education, 3(3), 242-257. doi: 10.5465/AMLE.2004.14242103

Dimov, D. (2011). Grappling with the unbearable elusiveness of entrepreneurial opportunities. Entrepreneurship Theory and Practice, 35(1), 57-81. doi: 10.1111/j.1540-6520.2010.00423.x

Drucker, P. F. (1998). The discipline of innovation. Harvard Business Review, 76, 149-157. 
Duval-Couetil, N. (2013). Assessing the impact of entrepreneurship education programs: challenges and approaches. Journal of Small Business Management, 51(3), 394-409. doi: 10.1111/jsbm. 12024

Eckhardt, J., \& Shane, S. (2013). Response to the commentaries: the individual-opportunity (IO) nexus integrates objective and subjective aspects of entrepreneurship. Academy of Management Review, 38(1), 160-163. doi: 10.5465/amr.2012.0192

Faia, V. S., Rosa, M. A. G., \& Machado, H. P. V. (2014). Alerta empreendedor e as abordagens causation e effectuation sobre empreendedorismo. Revista de Administração Contemporânea, 18(2), 196-216. Recuperado de http://www.scielo.br/pdf/rac/v18n2/v18n2a06.pdf. doi: $10.1590 / \mathrm{S} 1415-65552014000200006$

Fiet, J. O., \& Patel, P. C. (2006). Entrepreneurial discovery as constrained, systematic search. Small Business Economics, 30(3), 215-229. doi: 10.1007/s11187-006-9010-5

Fisher, G. (2012). Effectuation, causation, and bricolage: a behavioral comparison of emerging theories in entrepreneurship research. Entrepreneurship Theory and Practice, 36(5), 1019-1051. doi: 10.1111/j.1540-6520.2012.00537.x

Gartner, W. B. (1988). "Who is the entrepreneur?" is the wrong question. American Journal of Small Business, 12(4), 11-32.

Haltiwanger, J., Jarmin, R., \& Miranda, J. (2009). Business dynamics statistics briefing: jobs created from business startups in the United States. Kansas City, MO: Ewing Marion Kauffman Foundation.

Katz, J. A. (2003). The chronology and intellectual trajectory of American entrepreneurship education. Journal of Business Venturing, 18(2), 283-300. doi: 10.1016/S0883-9026(02)00098-8

Kirzner, I. M. (1979). Perception, opportunity, and profit: studies in the theory of entrepreneurship. Chicago: University of Chicago Press.

Lange, J. E., Mollov, A., Pearlmutter, M., Singh, S., \& Bygrave, W. D. (2004). Pre-startup formal business plans and post-startup performance: a study of 116 new ventures. Wellesley: Babson College.

March, J. (1978). Bounded rationality, ambiguity, and the engineering of choice. The Bell Journal of Economics, 9(2), 587-608. doi: 10.2307/3003600

Maritz, A., \& Brown, C. (2013). Enhancing entrepreneurial self-efficacy through vocational entrepreneurship education programmes. Journal of Vocational Education and Training, 65(4), 543-559. doi: 10.1080/13636820.2013.853685

McClelland, D. C. (1961). The achieving society. Princeton: Van Nostrand Co.

McMullan, W., \& Long, W. (1987). Entrepreneurship education in the nineties. Journal of Business Venturing, 2(3), 61-275. doi: 10.1016/0883-9026(87)90013-9

Mintzberg, H. (1978). Patterns in strategy formation. Management Science, 14(9), 934-948. doi: 10.1287/mnsc.24.9.934

Mitchell, R. K., Busenitz, L., Lant, T., McDougall, P., Morse, E. A., \& Smith, B. (2002). Toward a theory of entrepreneurial cognition: rethinking the people side of entrepreneurship research. Entrepreneurship Theory and Practice, 27(2), 93-104. doi: 10.1111/1540-8520.00001

Neck, H., \& Greene, P. (2011). Entrepreneurship education: known worlds and new frontiers. Journal of Small Busines Management, 49(1), 55-70. doi: 10.1111/j.1540-627X.2010.00314.x 
Osterwalder, A., \& Pigneur, Y. (2010). Business model generation. Hoboken, New Jersey: John Wliey $\&$ Sons, Inc.

Perry, J. T., Chandler, G. N., \& Markova, G. (2012). Entrepreneurial effectuation: a review and suggestions for future research. EntrepreneurshipTheory and Practice, 36(4), 837-861. doi: 10.1111/j.1540-6520.2010.00435.x

Read, S., Sarasvathy, S., Dew, N., Wiltbank, R., \& Ohlsson, A.-V. (2011). Effectual entrepreneurship. New York, NY: Routledge.

Read, S., Song, M., \& Smit, W. (2009). A meta-analytic review of effectuation and venture performance. Journal of Business Venturing, 24(6), 573-587. doi: 10.1016/j.jbusvent.2008.02.005

Rideout, E. C., \& Gray, D. O. (2013). Does entrepreneurship education really work? A review and methodological critique of the empirical literature on the effects of university-based entrepreneurship education. Journal of Small Business Management, 51(3), 329-351. doi: $10.1111 /$ jsbm. 12021

Ries, E. (2011). The lean startup: how today's entrepreneurs use continuous innovation to create radically successful businesses. New York, NY: Crown Publishing.

Sarasvathy, S. D. (2001a). Causation and effectuation: toward a theorial shift from economic inevitability to entrepreneurial contigency. Academy of Management Review, 26(2), 243-263. Retrieved from http://www.jstor.org/stable/259121

Sarasvathy, S. D. (2001b, August). Effectual reasoning in entrepreneurial decision making: existence and bounds. In Academy of Management Proceedings, 2001(1), D1-D6. doi: 10.5465/APBPP.2001.6133065

Sarasvathy, S. D. (2004). The questions we ask and the questions we care about: reformulating some problems in entrepreneurship research. Journal of Business Venturing, 19(5), 707-717. doi: 10.1016/j.jbusvent.2003.09.006

Sarasvathy, S. D. (2008). Effectuation: elements of entrepreneurial expertise. Massachussets, USA: Edward Elgar Publishing, Inc.

Sarasvathy, S. D., \& Dew, N. (2005). New market creation through transformation. Journal of Evolutionary Economics, 15(5), 533-565. doi: 10.1007/s00191-005-0264-x

Sarasvathy, S. D., \& Venkataraman, S. (2011). Entrepreneurship as method: open questions for an entrepreneurial future. Entrepreneurship Theory and Practice, 35(1), 113-135. doi: $10.1111 / \mathrm{j} .1540-6520.2010 .00425 . x$

Sarfati, G. (2013). Estágios de desenvolvimento econômico e políticas públicas de empreendedorismo e de micro, pequenas e médias empresas (MPMEs) em perspectiva comparada: os casos do Brasil, do Canadá, do Chile, da Irlanda e da Itália. Revista de Administração Pública, 47(1), 25-48. doi: 10.1590/S0034-76122013000100002

Shane, S. (2012). Reflections on the 2010 AMR decade award: delivering on the promise of entrepreneurship as a field of research. Academy of Management Review, 37(1), 10-20. doi: 10.5465/amr.2011.0078

Simon, H. A. (1959). Theories of decision-making in economics and behavioral science. The American Economic Review, 49(3), 253-283. doi: 10.2307/1809901

Solomon, G. T., Duffy, S., \& Tarabishy, A. (2002). The state of entrepreneurship education in the United States: a nationwide survey and analysis. International Journal of Entrepreneurship Education, $1(1), 65-86$. 
Tasic, I., \& Andreassi, T. (2008). Strategy and entrepreneurship: decision and creation under uncertainty. Journal of Operations and Supply Chain Management, 1(1), 12-23. doi: 10.12660/joscmv1n1p12-23

Venkataraman, S., Sarasvathy, S. D., Dew, N., \& Forster, W. R. (2012). Reflections on the 2010 AMR decade award: whither the promise? Moving forward with entrepreneurship as a science of the artificial. Academy of Management Review, 37(1), 21-33. doi: 10.5465/amr.2011.0079

Vesper, K., \& Gartner, W. (1997). Measuring progress in entrepreneurship education. Journal of Business Venturing, 12(5), 403-421. doi: 10.1016/S0883-9026(97)00009-8

Weick, K. (1979). The social psychology of organizing. Reading, MA: Addison-Wesley.

Wennekers, S., \& Thurik, R. (1999). Linking entrepreneurship and economic growth. Small Business Economics, 13(1), 27-55. doi: 10.1023/A:1008063200484

Yin, R. K. (2001). Estudo de caso: planejamento e métodos. Daniel Grassi (2a ed.). Porto Alegre, RS: Bookman.

\section{Dados dos Autores}

Marcus Alexandre Yshikawa Salusse

Rua Itapeva, 432, 01332-000, São Paulo, SP, Brasil. E-mail: marcus.salusse@ gvmail.br

Tales Andreassi

Rua Itapeva, 432, 01332-000, São Paulo, SP, Brasil. E-mail: tales.andreassi@fgv.br 